\title{
An Empirical Analysis of the Socioeconomic and Demographic characteristics influencing Birth Certification in Nigeria
}

Uchechi Shirley Anaduaka ( $\sim$ usanaduaka@gmail.com )

Research article

Keywords: Birth certification, Early Childhood, Multilevel modeling, DHS, Nigeria

Posted Date: July 30th, 2020

DOI: https://doi.org/10.21203/rs.3.rs-18158/v3

License: (c) (i) This work is licensed under a Creative Commons Attribution 4.0 International License.

Read Full License 
An Empirical Analysis of the Socioeconomic and Demographic characteristics influencing Birth Certification in Nigeria

Uchechi Shirley Anaduaka ${ }^{1 *}$

\begin{abstract}
Background: Promoting birth certification is instrumental to achieving target 16.9 of the Sustainable Development Goals: legal identity for all by 2030. However, limited research has investigated the determinants of birth certification of children in the subSaharan African context. This study analyzes the socioeconomic and demographic factors associated with the birth certification of children under-five years in Nigeria.
\end{abstract}

Methods: The study employed three rounds of the Nigerian Demographic and Health Survey involving 79487 children (0-4 years) in Nigeria. Birth certification was defined as whether a parent/caregiver had a child's birth certificate at the time of the interview. Ordinary least squares and multilevel logistic regression models established the relationships between the socioeconomic and demographic factors and birth certification.

Results: Children under-five years who had a skilled attendant at birth, at least one vaccination, and maternal access to prenatal visits had about $25.6 \%, 60.5 \%$ and $35.0 \%$ higher odds of having their births certified. Children born to more educated mothers and fathers had 1.023 and 1.012 times the odds of birth certification. Children from average and rich households also had $13.2 \%$ and $34.2 \%$ higher odds of birth certification, respectively. Conversely, child age, higher birth order, longer birth intervals, polygyny, having at least two dead siblings, father being employed in a low skilled job, living far from a registration center and in a poor community are risk factors for birth certification. Maternal age at birth and paternal has non-linear, albeit weak effects on birth certification. Being large at birth, bank account ownership were also significant predictors of birth certification. Mixed effects were noted for religion, ethnicity and region. Finally, no significant effects were noted for gender, maternal occupation and rural residence.

Conclusions: The findings identify several socioeconomic and demographic factors associated with birth certification suggesting possible risks with improving birth certification in Nigeria. Access to health care and higher socioeconomic backgrounds are significant protectors of and distance to registration centers as obstacles to birth certification for children in Nigeria. Public policy strategies should encourage the use of health care services and also increase the number of registration centers in Nigeria.

Keywords: Birth certification; Socioeconomic and demographic determinants, Early Childhood; Multilevel modeling; Demographic and health Survey; Nigeria; sub-Saharan African context

\footnotetext{
*Correspondence: usanaduaka@hkbu.edu.hk; usanaduaka@gmail.com

${ }^{1}$ Department of Economics, Faculty of Business, Hong Kong Baptist University, The Wing Lung Bank Building for Business Studies, Shaw Campus, 34 Renfrew Road, Kowloon Tong, Hong Kong.
} 


\section{Background}

In the past decade, child protection indicators such as birth registration (BR) have been incorporated into the development goals agenda [Error! Reference source not found.]. For instance, target 16.9 of the Sustainable Development Goals (SDG) suggests a legal identity for all, by 2030. The United Nations Convention on the Rights of the Child (UNCRC) notes that BR is a child's 'first right' and is critical to improvements in human capital outcomes: utilization of healthcare services and educational attainment [Error! Reference source not found.], as it provides the legal 'membership card' to participate in the society [Error! Reference source not found., Error! Reference source not found.]. Without being registered, a child will be born and die without any trace of their existence documented officially. This is known as the scandal of invisibility - being unseen, uncountable, and hence uncounted [5-7]. BR is defined as "the continuous, permanent, and universal recording within the civil registry, of the occurrence and characteristics of births in accordance with the legal requirements of a country" [8]. Universal BR is also a public good used to monitor the progress of development goals and functioning of the rule of law in modern societies $[9,10]$. As a proof of BR, registered children are issued a birth certificate, their proof of a legal identity which ensures that their human rights are not overlooked when violated or abused [Error! Reference source not found., 11, 12]. This valid proof of age can mitigate longterm risks, by making it easier to claim rights and/or privileges in the future e.g., formal labor market participation, civil marriage registration, bank account ownership, owning/inheriting land and houses, accessing social welfare programs (e.g. scholarships, food-assistance, insurance and pensions), voting and obtaining a passport for international travel [13-16]. In some countries, birth certificates are required for enrollment, taking tests and examinations, scholarship applications as well as graduation for primary and secondary schools [17]. Despite significant improvements in birth registration rates between 2008 and 2018, 57.4\% of Nigerian children under-five years still have their births unregistered and are at risk of 
statelessness [18]. Moreover, $53.8 \%$ of the registered children lack a birth certificate. ${ }^{2}$ The non-documentation rates of births in Nigeria is among highest in the world, and ranks higher than Sub-Saharan Africa (55\%), and West and Central Africa (49\%) [19]. To address this 'scandal of invisibility', it is important to identify the key drivers of birth registration, and then implement well-targeted policies. For example, some children may not be registered due to the low number of BR centers in their community (low supply), while others may be due to being born into low-income families or poorly educated parents (low demand).

Analyzing which factors drive BR in the developing world is relatively new, as most of the empirical papers span the past decade, given the poor availability of data before then. With increased access to data, extant studies have identified some significant socioeconomic and demographic (SED) characteristics which influence BR rates: gender of the child (Nigeria) [20]; perinatal health services (Edo, Nigeria; Nusa Tenggara, Indonesia) [21, 22]; mother's age at child's birth (Ghana; Western Australia; Bolivia, Brazil, Colombia, the Dominican Republic, Peru, and Nicaragua) [23-25]; maternal health-seeking behavior (Bauchi and Cross-River, Nigeria) [26]; parent's literacy and education (Lombok, Indonesia; Ghana) [27, Error! Reference source not found.8]; wealth and parent's marital status (Indonesia; Dominican Republic) [5, 29]; and geographical location (Bolivia, the Dominican Republic, and Peru) [30].

It is important to note that many of the studies exist in a different context, and analyzing whether these factors play out in Nigeria using a nationally representative dataset makes for an important contribution. The findings will evidence for policy makers to better understand

\footnotetext{
${ }^{2}$ Birth certification and registration rates may differ for several reasons. First, parents may begin but not complete the registration process. This may be due to issues with payment of fees. The Nigerian law states that the birth registration should be free, registration offices can charge penalties for late registration. As no fixed figures are given by law, the rates could become exorbitant and prevent parents from registration the child. Another reason is that some mothers may mistake the notification of a live birth, issued at the time of delivery for the birth certificate. Finally, some parents could have lost or have not picked up the birth certificate and so could not provide it at the time of the interview. These reasons are currently speculative and would further research before conclusions are drawn.
} 
the drivers of BR in Nigeria. In addition, none of the studies on Nigeria analyze the SED characteristics using different waves of the Nigerian Demographic \& Health Survey (NDHS) whilst simultaneously accounting for the hierarchical structure of the data. The present study, therefore, examined the role of several indicators of socioeconomic and demographic factors associated with $\mathrm{BC}$ for children under-five years using three rounds of the nationally representative NDHS data. We use BC instead of BR as the outcome variable to reduce the extent of misreporting and recall bias that is common in survey data.

\section{Study Context}

Nigeria is the most populous country south of the Sahara and ranks 7th globally. Presently, it is divided into six geo-political regions: North-Central (NC), North-East (NE), North-West (NW), South-East (SE), South-South (SS) and South-West (SW), and 37 administrative states $^{3}$. The country is a viable study setting given the low prevalence of BC coupled with significant variations in SED characteristics. ${ }^{4}$ Three ethnicities (Hausa/Fulani, Igbo and Yoruba) dominate the cultural sphere: the Hausa/Fulani people in the north, the Igbo and Yoruba ethnicities in the SE and SW, respectively. Also, the north and south are divided across religious lines, with Islam primarily in the north, and Christianity in the south. With these differences, it is crucial that an effective civil registration and vital statistics system that provides credible information on vital events from births to deaths (including fetal deaths) is in place. In Nigeria, this responsibility falls on the National Population Commission (NPC), a centralized organization established in 1988 and charged with two core responsibilities: to carry out civil registration and undertake periodic enumeration of the population through sample surveys and censuses. The legal framework for birth registration is Births, Deaths, Etc. (Compulsory Registration) Act, No. 69 (14 December 1992). ${ }^{5}$ Since 2003, following the

\footnotetext{
${ }^{3}$ The 37 administrative states are the 36 states and the Federal Capital Territory (FCT).

${ }^{4}$ It also has significant cultural differences with more than 300 ethnic and three main religious groups.

5 See https://data.unicef.org/crvs/nigeria/ for more details on the Compulsory Registration Act.
} 
introduction of the Child Rights Act, parents/guardians were legally obligated to register the birth of their child within the first 60 days [20]. ${ }^{6}$ Consequently, the NPC set a target of Universal Birth Registration (100\%) by 2015. However as at 2018, this mandate has fallen below par, as less than $43 \%$ of children have their births registered, and only $20.6 \%$ have their births certified [18].

\section{Methods}

\section{Sample and Design}

This analysis was based on the 2008, 2013 and 2018 rounds of the nationally representative NDHS data, a repeated cross-sectional standardized survey on demographic and health characteristics of Nigerian households (HHs). ${ }^{7,8 .}$ The eligible HHs are selected using a multistage stratified random cluster sampling technique with considerations for urban and rural areas. First, clusters are drawn from an official list of enumeration areas (EAs) based on the 2006 census. ${ }^{9}$ Secondly, HHs are randomly selected from the list of clusters. Finally, every eligible woman (aged 15-49 years) in the selected $\mathrm{HH}$ is interviewed and asked to provide information on herself, her children and spouse/partner (if available). A total of 80, 899 children had line numbers which allowed for matching to the birth registration information in the household member recode. The final sample was restricted to children born to mothers currently or formerly in a union, to allow capture information on mother's spouse/partner. Following the sample restrictions, 79,487 children born to 54,446 mothers from 3,171 communities and 37 states during 2008-2018 period were deemed suitable for the analysis.

\section{Measures \\ Birth certification}

\footnotetext{
${ }^{7}$ The data was collected by the Macro International Inc., Calverton, Maryland in cooperation with the U. S. Agency for International Development (USAID), the NPC, and the Federal Ministry of Health. ${ }^{8}$ In the 2018 wave, 40, $427 \mathrm{HHs}$ were successfully interviewed, equivalent to a $99 \%$ response rate. The response rates for women was equally high at $99 \%$, as 41,821 women out of 42, 121 who were sampled were successfully interviewed.

${ }^{9}$ The household clusters usually correspond to small villages or blocks within larger villages or cities.
} 
Studies have shown that using self-reported variables can introduce bias. For example, [32] notes that self-reporting bias could underestimate the exact values and thus threaten study findings. This study, hence, employed $\mathrm{BC}$ as a more robust definition of $\mathrm{BR}$. BC was computed from responses to the following question: 'Does (NAME) have a birth certificate?'. The responses were coded as a binary variable categorized as Yes=1 if the child had a birth certificate and 0 , otherwise.

\section{Explanatory variables}

The role of 4 categories (child, parent, household and community) of SED characteristics were considered in the analyses due to their potential effects on BC. The theoretical framework classifying the SED characteristics are based on the propositions made by [33] to study child survival. The assumption is that these proximate determinants of child survival are most likely related to the underlying factors that affect a child's probability of being certified.

\section{Child-level characteristics}

Seven characteristics were included as measures of the child's demographic information: gender $(0=$ female, $1=$ male $)$, age-in-months, collapsed into five cohorts $(1=<12,2=12-23$, $3=24-35,4=36-47,5=48-59)$, birth order $\left(1=1^{\text {st }}\right.$ child, $2=2^{\text {nd }}$ child, $3=3$ rd child, $4=4^{\text {th }}$ or higher order birth), size-at-birth (1=small, $2=$ average, $3=$ large $)^{10}$, birth interval (years), skilled birth attendant (SBA, $0=$ No, $1=$ Yes $)$ and vaccination status $(0=0,1=1+)$.

\section{Parent-level characteristics}

At the mother-level, I included her age at birth (collapsed into five cohorts $(1=<20$ years, $2=20-24,3=25-29,4=30-34,5=35+)$, prenatal visits $(0=0,1=1+)$, polygynous $(0=$ No, $1=$ Yes $)$, access to mass media $(0=\mathrm{No}, 1=\mathrm{Yes})$, whether she is a decision-maker $(0=\mathrm{No}, 1=\mathrm{Yes})^{11}$, and

\footnotetext{
${ }^{10}$ The size at birth is a commonly used proxy for the child's birth weight as the latter is not available for most of the children in the sample. It has been reported as a good measure for the child's birth weight [34].

${ }^{11}$ This is constructed based on the mother's self-report that she contributes to decisions made on her health care, making large $\mathrm{HH}$ purchases and visits to family or relatives.
} 
whether she had lost at least two children $(0=\mathrm{No}, 1=\mathrm{Yes})$. The current age of the father was also included in the analysis (collapsed into five cohorts $(1=<25$ years, $2=25-34,3=35-44$, $4=45-54,5=55+)$. In addition to these variables, I included the mother- and father's education (years) and occupation (1=low skill, $2=$ medium skill, $3=$ high skill, $4=$ other). ${ }^{12}$

\section{Household-level characteristics}

At the $\mathrm{HH}$ level, four variables were employed: Owns a bank account ( $0=\mathrm{No}, 1=$ Yes), wealth index ( $1=$ poor, $2=$ average, $3=$ rich); religion $(1=$ Islam, $2=$ Christian, $3=$ other $)$, and ethnicity (1=Hausa/Fulani ${ }^{13}, 2=$ Igbo, $3=$ Yoruba, $4=$ others). Given that NDHS does not collect income or consumption data, the wealth index is composite measure of the HH's living standards and is calculated using data on a HH's ownership of selected assets [35, 36]. The computed weights generated using the principal components analysis make more sense as it places HHs on a continuous relative wealth scale. The HHs are then distributed into one of five quintiles, ranging from one for the poorest fifth to five for the wealthiest fifth. ${ }^{14}$

\section{Community and state-level characteristics}

The community-level characteristics were measured at the level of the geographic 'cluster' of the HH. At the community (cluster) and state-levels, seven variables were employed: place of residence $(0=$ urban, $1=$ rural $)$, distance to registration centers and the nearest major road $(1=<5 \mathrm{kms}, 2=5-9.99 \mathrm{kms}, 3=10+\mathrm{kms})$, altitude (in meters above sea level) $(1=$ low $(<316)$, $2=$ medium (316-443), 3=high $(>443))$, mean of female and male education, proportion of poor HHs, the mean of children who have died in the community, and region of residence $(1=\mathrm{NC}, 2=\mathrm{NE}, 3=\mathrm{NW}, 4=\mathrm{SE}, 5=\mathrm{SS}, 6=\mathrm{SW})$. The altitude was categorized as low if the value was lower than the median, average between the median and the $75^{\text {th }}$ percentile, and high if

\footnotetext{
${ }^{12}$ Collapsing the child's age, mother's age at birth and the father's age into cohorts allows the possibility of checking the existence of a nonlinear relationship.

13 These ethnicities are grouped on the basis that they speak a common language or dialect, share a common sense of identity, cohesion and history; or have a single set of customs and behavioral norms e.g. marriage, clothing, diet, and taboos [37].

${ }^{14}$ For a detailed discussion on the use of asset indices to capture the wealth status of HHs, see [36]. For a more detailed description on how the wealth index is constructed, see [38].
} 
the value was above the $75^{\text {th }}$ percentile. The distance to the nearest registration center and road, and the altitude (meters above sea level) are indicators of geographic accessibility.

\section{Methods used for Modelling}

First, a univariate analysis using descriptive statistics was employed to describe the characteristics of sample. Means and standard deviations were used to represent the categorical and continuous variables, and a two-sample mean-comparison test (ttest) was used to check the differences between the certified and non-certified groups. Finally, a range of multivariate analysis using OLS (not reported) and multilevel logistic regression models (MLRM) were employed to analyze the relationship between the SED characteristics and BC. The MLRM was employed to account for the binary nature of the outcome variable and the hierarchical structure of the NDHS data. The children $i$ are clustered within communities $j$, and communities within states $k$. The MLRM also helps prevent misleading conclusions about the relative importance of the different sampling levels on the child's BC [39].

\section{Multilevel model Specification}

The specific form of the three-level MLRM is presented below:

$$
\begin{gathered}
\operatorname{Logit}\left(B C_{i j k}\right)=\log \frac{B C_{i j k}}{1-B C_{i j k}}=\alpha_{j k}+\beta X_{i}+\epsilon_{i} ; \text { for } i=1, \ldots, I \\
\alpha_{j k}=\gamma_{0}^{j}+\gamma_{k}+\epsilon_{j} ; \text { for } j=1, \ldots, J, k=1, \ldots, K \\
\gamma_{k}=\lambda_{0}^{k}+\lambda_{k} S_{k}+\epsilon_{k} ; \text { for } k=1, \ldots, K
\end{gathered}
$$

Where $B C_{i j k}$ is the probability of $\mathrm{BC}$ for child $i$ living in community $j$ within state $k$, and $\beta$ is a vector which contains the estimates for the explanatory variables. $\gamma_{0}^{j}$ and $\gamma_{k}$ are the community- and state-level intercepts, each of which is a function of the state-level variable $S_{k}$, state-level coefficients $\lambda_{k}$, and the state-level intercept $\lambda_{0}^{k}$. Finally, $i, j$ and $k$ are the error terms at the child-, community- and state-levels, respectively. The random intercepts of $\gamma_{0}^{j}$ (between communities) and $\lambda_{0}^{k}$ (between states) variance is assumed to follow a normal distribution with mean zero and the covariance matrix for a three-level model. Four models were fitted: Model 0 (Empty model) was fitted without any explanatory variables to test the 
random effects (REs) in the intercept and estimate the intraclass correlation coefficient (ICC) at the community and state levels. For each additional model, I add a category of indicators and in Model 4, all the explanatory variables were controlled for. Year-and-month dummies for the interview and the child's birth were also included in the additional models, to account for the differences in lag lengths and potential observed and unobserved heterogeneity in trends across space and time [40].

The beta $(\beta)$ estimates are the fixed effects (measures of association) which capture the overall average relationship between $\mathrm{BC}$ and the explanatory variables. They are expressed as odds ratios (OR) with their $95 \%$ credible intervals, and a p-value $<0.05$ (two-tailed test) was considered statistically significant. Moreover, the random effects are the measures of variation in birth certification across communities and states expressed as ICC, the proportional change in variance (PCV), and the median odds ratio (MOR). In a MLRM, the individual (first) level has a standard logistic distribution with variance $\pi^{2} / 3$ which approximates to $3.29 .{ }^{15}$ The ICC is calculated as $\left[\mathrm{ICC}=V_{a}+V_{b}+\frac{\pi^{2}}{3}\right]$, where $V_{a}$ and $V_{b}$ are the area level variances, respectively. ${ }^{16}$ It is used to evaluate which neighborhood context is more relevant in explaining the variation in the outcome variable [39, 41-42]. The larger the ICC, the lower (higher) the variability is within (between) the areas [39].The PCV which indicates the additional effects of the included variables is calculated as $\left[\mathrm{PCV}=\frac{V_{e}-V_{m}}{V_{e}}\right]$, where $V_{e}$ is the variance in the empty model and $V_{m}$ variance in the successive models. Finally, the MOR is calculated as $\left[\mathrm{MOR}=\exp \left(2 \sigma_{\mu}^{2} \phi^{-1}(0.75)\right)\right]$, where $\phi^{-1}$ is the inverse cumulative standard normal distribution function. In simple terms, the MOR is the median odds of being certified when a child moves from an area with a low to an area with a high

\footnotetext{
${ }^{15} \pi$ denotes the mathematical constant 3.1416 and not the probability.

${ }^{16}$ The ICC is calculated based on the widely adopted latent response formulation that assumes a latent continuous response underlies the observed binary response.
} 
probability of BC. The higher the MOR, the larger the general contextual effect. If the MOR is equal to 1 (i.e. $\sigma_{\mu}^{2}=0$ ), it implies the absence of a neighborhood variation.

It is important to note that the non-numerical based categorical variables - gender, size-atbirth, religion, ethnicity, and place of residence - are effect-coded (yield a sum to zero constraint) for the regressions. In the case of two distinct values (e.g. gender) this will have values 1 and -1 [43]. When compared to dummy-coded variables, effect-coded variables have a greater speed of convergence and mixing of sampled parameters in the Markov Chain Monte Carlo (MCMC) based Bayesian estimation of the multilevel models [44]. For each model, a burn-in and monitoring chain length of 5,000 and 10,000 iterations are used, respectively.

Finally, the Bayesian Deviance Information Criterion (DIC) introduced by [45] is used to compare the goodness-of-fit of the models. The Bayesian DIC suggests a trade-off between the complexity and deviance of the model. Models with smaller DIC are preferred to models with higher DIC, and a difference of 5 or more considered substantial. The data was analyzed using Stata version 14 [46], and normalized sampling weights were included in the model to adjust for non-responses and ensuring that the findings can be generalized to the general population [37]. The MLRM with Binomial, Penalized Quasi Likelihood (PQL) of order-2 and MCMC estimation methods [47] were applied using the runmlwin command available in Stata 14 which allows researchers to combine the best features of Stata for Windows (Stata Corporation Inc., College Station, TX, USA) and the MLwiN version 3.04 software [48].

\section{Results}

\section{Regional- and state-level distribution of birth certification in Nigeria}

Table 1 presents the regional- and state-level distributions of BC in Nigeria between 2008 and 2018. Overall, only $16.14 \%$ of children have their births certified. At the regional level, the $\mathrm{BC}$ rates range from $11.91 \%$ in the NE to $26.84 \%$ in the SW. At the state level, the values range from $2.10 \%$ in Zamfara state $(\mathrm{NW})$ to $33.43 \%$ in Oyo state (SW). Moreover, $70 \%$ of 
the top ten states are in the south (Anambra, Edo, Ekiti, Lagos, Nasarawa, Ondo, Osun and Oyo states). The gap between Zamfara (lowest BC state) and the best-performer was $31.33 \%$. Among the 10 worst performing states, the North accounts for $80 \%$ of the states and the NW accounts for $40 \%$ of the states in the group. Following Zamfara state in order of rank is: Sokoto (NW, 2.94\%), Kebbi (NW, 5.82\%), Bayelsa (SS, 6.81\%), Niger (NC, 7.66\%), Bauchi (NE, 7.99\%), Plateau (NC, 8.84\%), Yobe (NE, 9.01\%), Jigawa (NW, 9.13\%), and CrossRiver (NW, 11.61\%). The North-South gap is not surprising as it has been documented in various studies for a wide range of development outcomes [49-51].

\section{Insert Table 1 here}

\section{Socioeconomic and demographic characteristics of participants.}

Table 2 shows the characteristics of the 79,487 children included in the analysis. Male and twin children make-up $51 \%$ and $1 \%$ of the sample, respectively, and no statistical differences were noted between the certified and non-certified groups. Among the children whose data were analyzed, $22 \%$ were aged $0-11$ months and $19 \%$ aged $48-59$ months. In terms of the birth order, it is common knowledge that fertility rates among Nigerian women are higher than the global average of 2.5 births [52]. This is evident as $49 \%$ of children are in the 4th or higher-order birth order. Furthermore, $15 \%$ were small and $43 \%$ were large at birth. This variable is included in the analysis due to the suggestions in the literature that parental investments can be responsive to the initial child health endowments [53]. In addition, 36\% had a SBA and $63 \%$ had at least one vaccination on record. Finally, the mean interval between births was 2.9 years.

Among the mothers, $11 \%$ were adolescents at the time of the child's birth, $98 \%$ were in a union (married or cohabiting) and $33 \%$ were in a polygynous union. ${ }^{17}$ According to the WHO, women should be encouraged to have prenatal care visits during pregnancy at: 1) 8-

\footnotetext{
${ }^{17}$ According to UNICEF, young mothers fall into the age category of 15-24, with adolescent mothers aged 15-19 (see https://data.unicef.org/topic/child-health/adolescent-health/ for details).
} 
12; 2) 24-26; 3) 32, and 4) 36-38 weeks, respectively [54]. Prenatal visits are an indicator for contact with skilled health personnel, as it is assumed that mothers with contact are likely to receive information on the birth registration process, and thus likely to start and/or complete the process. Within the sample, $73 \%$ mothers had at least one prenatal visit. Moreover, $57 \%$ contribute to decisions made within the $\mathrm{HH}, 58 \%$ also had access to media (TV, radio or newspaper), and $15 \%$ had lost at least two of their children. The fathers in the sample are older, with $2 \%$ aged less than 25 years and $8 \%$ in the $55+$ category. In this analysis, the parents' total years of schooling was used as an indicator for education. Education is very low with a mean of five and seven years of schooling for the mothers and fathers, respectively. Given that complete primary education is six years, this implies that most of the mothers have incomplete primary education and while the fathers just get by completing primary education. Parental education has been noted in the human capital literature as an important determinant of child development. More educated parents are more likely to choose better options for their children, to enhance future economic and social mobility [54]. Furthermore, only a handful of parents are engaged in high-skilled (professional, technical or managerial) jobs. For instance, only four percent of mothers and $10 \%$ of fathers are employed in high-skilled jobs. This is not surprising given the low rate of parental education in Nigeria.

On average, $35 \%$ of HHs own a bank account which suggests poor access to formal institutions in Nigeria. $47 \%$ are poor, $59 \%$ practice Islam and $40 \%$ are from the Hausa/Fulani ethnic group. $68 \%$ of $\mathrm{HHs}$ live in rural areas and $47 \%$ live in poor communities. In addition, $29 \%(71 \%)$ live at least $10 \mathrm{kms}$ from the nearest registration centers (roads). Also, $49 \%$ live in low and $28 \%$ in high altitude communities. On average, community average of parental education ranges from five years (female) to six years (male), and the community mean of mortality is 0.58 children. The SW region which accounts for the highest birth registration 
rates in Nigeria, accounts for $12 \%$ of the children within the sample. Finally, the NW which has the highest number of low BC states accounts for $30 \%$ of the sample.

\section{Insert Table 2 here}

\section{Multilevel Logistic Regression}

The fixed effects (measure of association) for BC are presented in Table 3. In model 1 only child-level variables were added, and the results revealed that being large at birth, having a SBA and being vaccinated were significant predictors of BC. In model 2, the family level characteristics were added. The results showed that prenatal visits, bank account ownership, being a Christian and from the Yoruba ethnic group was significantly associated with BC. In addition, the likelihood of $\mathrm{BC}$ increases with parental education and the wealth status of the HH. Moreover, maternal age at birth had a non-linear effect on the likelihood of BC. After controlling for the child, family and community level characteristics in model 3, children in the fifth year of life (48-59 months) had $41.6 \%$ lower odds of $\mathrm{BC}[\mathrm{OR}=0.584$, 95\%CI: 0.439-0.781] as compared to children in their first year of life ( $<12$ months). Regarding size at birth, children who were large at birth had $8.3 \%$ higher [OR=1.083, 95\% CI: 1.037-1.129] odds of BC compared to children who were small at birth. The results also suggest that birth interval is associated with 0.982 lower [OR=0.982; 95\%CI: 0.967 0.998] odds of BC. Looking at access to health services, children with a SBA were $25.6 \%$ $[\mathrm{OR}=1.256,95 \% \mathrm{CI}: 1.162-1.359]$; children who had at least one vaccination were $60.5 \%$ $[\mathrm{OR}=1.605,95 \% \mathrm{CI}: 1.469-1.742]$ more likely to have their births certified, compared to those children without a SBA or no vaccinations.

Keeping other variables constant, mothers who were 25-29 years at the time of the child's birth had $15.2 \%$ higher [OR=1.152, 95\%CI: 0.999-1.349]; mothers who were 30-34 years at the time of the child's birth had $16.7 \%$ higher [OR=1.167, 95\%CI: 0.999-1.391]; mothers were $35+$ years at the time of the child's birth had $14.3 \%$ higher [OR=1.143, 95\%CI: 0.960 1.385] odds of BC than mothers were adolescents at the time of their child's birth. Looking at 
mother's marital status, children whose mothers are separated had 52.9\% lower [OR $=0.471$, 95\%CI: 0.310-0.691]; children whose mothers were divorced had 35.4\% lower [OR=0.646, 95\% CI: 0.426-0.910], odds of $\mathrm{BC}$ as compared to children whose mothers were in a union. A child whose mother had at least one prenatal visit has $35.0 \%$ higher $[\mathrm{OR}=1.350 ; 95 \% \mathrm{CI}$ : 1.221-1.487] odds of BC than those with no prenatal visits. Children born to polygynous mothers had $5.7 \%$ lower [OR=0.943; 95\%CI: $0.873-1.015]$ odds of $\mathrm{BC}$ than children born to monogamous mothers, however the effect is only significant at the $10 \%$ level. Having 2 or more dead siblings reduces the odds of BC by $17.4 \%$ [OR=0.826; 95\%CI: $0.747-0.914]$. The results also revealed that parental education is positively associated with $\mathrm{BC}$, an additional year of maternal schooling increased the odds of $\mathrm{BC}$ by 1.023 times [OR=1.023, 95\%CI:1.014-1.031] and paternal schooling increased the odds of BC by 1.012 times $[\mathrm{OR}=1.012,95 \% \mathrm{CI}: 1.004-1.020]$, respectively. Father's age also has a positive and nonlinear effect on BC, though the effect is significant at the 10\% level. Fathers aged 25-34 years were $23.9 \%$ [OR=1.239, 95\%CI:0.904-1.587]; fathers aged 35-44 years were $29.8 \%$ [OR=1.298, 95\%CI:0.948-1.672]; fathers aged 45-54 years were 26.1\% [OR=1.261, 95\%CI:0.896-1.646] and those aged 55+ were 25\% [OR=1.250, 95\%CI:0.879-1.647], more likely to have their children's births registered compared to young fathers ( $<25$ years). The results also revealed that having a father employed in a low-skill job decreases the odds of BC by $6.5 \%[\mathrm{OR}=0.935,95 \% \mathrm{CI}: 0.879-0.996]$.

At the household level, the results suggest that having a bank account increases the odds of BC by $59.6 \%$ [OR=1.596, 95\%CI:1.483-1.709]. Regarding wealth, children from middleincome HHs were 13.2\% [OR=1.132, 95\%CI:1.020-1.253]; children from rich HHs were $34.2 \%[\mathrm{OR}=1.342,95 \% \mathrm{CI}: 1.170-1.514]$ more likely to have their births certified as compared to those living in poor HHs. Christian children had $10.6 \%$ higher $[\mathrm{OR}=1.106$, 95\%CI:0.996-1.215] and children whose families practiced other religions had $12.6 \%$ lower 
[OR=0.874, 95\%CI:0.730-1.037] odds of BC as compared to children whose families practice Islam. In terms of religion, children from the Yoruba ethnic group have $16.8 \%$ higher [OR=1.168, 95\%CI:1.038-1.298]; children from minority ethnic groups had lower [OR=0.939, 95\%CI:0.869-1.016] odds of BC.

The results also revealed that children living at least 10kms from a registration center had $22 \%$ lower $[\mathrm{OR}=0.780,95 \% \mathrm{CI}: 0.649-0.934]$ odds of $\mathrm{BC}$ as compared to children living less than $5 \mathrm{kms}$ from a registration center. In addition, children living at least $10 \mathrm{kms}$ from a road had $27.4 \%$ higher [OR=1.274, 95\%CI:1.053-1.539] odds of $\mathrm{BC}$ as compared to children living less than $5 \mathrm{kms}$ from a road. Keeping other variables constant, children living in poor communities are $46.5 \%$ [OR=0.535, 95\%CI:0.391-0.707] less likely to have their births certified. Also, the higher the number of children who have died in the communities, the lower the odds of $\mathrm{BC}[\mathrm{OR}=0.771,95 \% \mathrm{CI}: 0.613-0.941]$. In addition, the higher the years of female education $[\mathrm{OR}=1.020,95 \% \mathrm{CI}: 1.000-1.050]$ and male education $[\mathrm{OR}=1.035$, 95\%CI:1.008-1.065] in the communities, the more likely the odds of BC. Looking at the region of residence, only the effects of residing in the NE and SS are statistically significant. Being resident in the NE is associated with 59.5\% higher [OR=1.020, 95\%CI:1.000-1.050]; and being resident in the SS is associated with $18.9 \%$ lower [OR=0.811, 95\%CI:0.560-1.071] odds of BC as compared to the residents of the SW.

\section{Insert Table 3}

The random effects (measures of variation) are presented in Table 4. The results of the empty model showed that there was a statistically significant variability in the odds of BC between communities $(\tau=2.580, \mathrm{p}$-value $=0.000)$ and states $(\tau=0.436$, p-value $=0.000)$. The ICC implied that $40.91 \%$ and $6.92 \%$ of the total variance in $\mathrm{BC}$ was attributed to differences in communities and states, respectively. The MOR suggests a five-fold increase in the median odds of $\mathrm{BC}$, if a child is moved to a community with a higher probability of $\mathrm{BC}$ (MOR = 
4.63). On the other hand, moving a child from one state to another with a higher probability of $\mathrm{BC}$, implies approximately a two-fold increase in the median odds of $\mathrm{BC}(\mathrm{MOR}=1.88)$. The ICC in Model 1 indicated that, 31.62\% and 4.00\% of the variation in BC was attributed to differences across communities and states, respectively. The PCV revealed that $37.29 \%$ $(53.90 \%)$ of the variance in BC across communities (states) was explained by the child-level characteristics. The MOR reduced slightly to 3.36 and 1.53 at the community- and statelevels, respectively. The ICC in Model 2 implied that differences between communities and states accounted for $26.28 \%$ and $2.86 \%$ of the variation in BC, respectively. Moreover, the PCV revealed that $52.75 \%$ and $69.95 \%$ of the variation in $\mathrm{BC}$ between communities and states was explained by child and family characteristics. After the inclusion of all the SED variables in Model 3, the variation in the odds of BC between communities $(\tau=1.198, \mathrm{p}$ value $=0.000)$ and states $(\tau=0.116, \mathrm{p}$-value $=0.000)$ remained statistically significant. The estimated ICC indicated that the differences between communities and states accounted for $25.98 \%$ and $2.52 \%$ of the variation in BC, respectively. The PCV showed that $53.57 \%$ (73.39\%) of the variation in BC across communities and states was explained by all the included variables in model 3. Finally, the MOR is higher than 1, which suggests that the heterogeneity evident in $\mathrm{BC}$ is substantial.

Insert Table 4 here

\section{Discussion}

This study was based on data from the 2008, 2013 and 2018 rounds of the Demographic and Health Survey conducted in Nigeria and employed multiple analytical approaches. The study has identified several socioeconomic and demographic characteristics associated with birth certification. The study findings revealed that access to health care services proxied by having a skilled attendant at birth being vaccination and prenatal visits has a positive significant influence on birth certification. The positive effects of health access on BR has been noted elsewhere by [20, 21, Error! Reference source not found., 29]. The possible 
explanation could be, children who have contact with health care services have higher chances of receiving relevant information on the need for and the process of BC. The child's size at birth also has a positive influence on BC. A possible explanation for this could be related to the argument that parents could reinforce cognitive resources, as parents may not be willing to make significant investments until they are sure they children will survive. The results also suggested non-linear effects of maternal age at birth on the likelihood of BC. This implies that the positive effects of the different age variables inflect at some point and the efforts to register the child's birth decreases. The non-linear effect of maternal age has been noted by [21] on birth registration in Nigeria, and by $[55,56]$ on other child health indicators in the Democratic Republic of Congo (DRC) and other low-and-middle income countries, respectively. Younger mothers may have lower socioeconomic status and schooling and older mothers are more likely to be busy pushing their career ambitions. Evidence suggests that children whose parents had higher years of schooling were more likely to be certified. This finding is in line with previous studies conducted on the determinants of birth registration in Nigeria and elsewhere [20] and [Error! Reference source not found., 30]. The possible reasoning for this could be, educated parents have more awareness of the benefits of $\mathrm{BC}$ and have greater capabilities to take actions regarding the process of $\mathrm{BC}$. In addition, wealth has a significant influence on BC. This finding is supported by a few studies on BR including [Error! Reference source not found., 5, 20, 25]. The reasoning behind this could be, richer parents are more aware of the importance of $\mathrm{BC}$ on the child's future mobility (for example, university education, participation in the formal job market and legal migration abroad). Higher education and wealth have also been linked to better decision-making as they are in a better position to earn money and afford the registration services [57, 58]. Paternal age also had a positive influence on $\mathrm{BC}$ which has not been noted elsewhere, however, the weak significance 
imply that more research needs to be carried out before causal inference can be drawn on it.

In this study, bank account ownership was found to be an important predictor on BC, which has not been noted anywhere else. However, it is not surprising as birth certificates are one of the requirements for opening a bank account in Nigeria. Mixed results were noted for the effect of culture (religion and ethnicity) on the likelihood of BC. In terms of religion, on one hand, children from Christian HHs are more likely whereas those whose family practice other forms of religion are less likely to be certified. Moreover, children from the Yoruba ethnic group had higher chances of being certified while those from minority ethnic groups are less likely to be certified compared to Hausa/Fulani children. Given that the Yoruba ethnic group are mostly in the South West, the results could be reflecting the fact that the SW has the highest $\mathrm{BC}$ rates over the reviewed period.

Notable deterrents to BC include child's age, longer birth intervals, marital status, child mortality, father working in a low skilled job, living far away from the registration center $(10+\mathrm{kms})$ and living in a poor community. The findings also revealed that the older children are less likely to have their births certified than newborn children. This is contrary to the findings of $[20,23]$ in Nigeria and Ghana. The probable reason for this is that newborn children are more likely to be in contact with health institutions (e.g. during post-natal visits and vaccinations), where their parents can be reminded of the need for BC. Children whose mothers are separated or divorced are less likely to be certified which has also been noted by $[21,60]$ on birth registration in Nigeria. Mothers in a union may have the assistance from a spouse or partner to care for the child(ren), while they deal with the process of BC. Also, the documentation on the process of BC in Nigeria states that both parents are needed to be available for the registration. This could act as a deterrent for non-married mothers to commit to BC. In addition, the study finds that polygynous children are less likely to be certified. 
While this finding has not been noted for $\mathrm{BC}$, it has been suggested in the literature that polygamy is associated with poor child welfare outcomes as polygynous parents are more likely to have lower education and socioeconomic status [59].

Mortality had a negative influence on BC. While this is a new finding, it is not surprising as mothers who higher mortality may be less willing to make the efforts to register any more children until they are sure that the child will survive and reap any benefits that may accrue to birth certification. This finding of the negative effect of distance to registration centers on BC has not been noted elsewhere for Nigeria, however, [5, 29, 30] reports similar findings for children living in Indonesia and selected countries in Latin America and the Caribbean. The findings of higher birth order, longer birth intervals and father's work status as significant obstacles to BC are also in line with other studies of birth registration [60-63].

Being of $4^{\text {th }}$ or higher order births also has a negative albeit weak influence on BC. The effect of birth order remains mixed in the literature on child development, however, a typical suggestion for the negative effect on $\mathrm{BC}$ is related to the delay in the benefits of birth registration. After the first child is born and is successfully registered and certified, without immediate returns to the certification it becomes less likely that later-born children will be registered. Another explanation for the negative effect of birth order lies in the resource dilution hypothesis. Older children are proxies for larger family size, and in larger families it is hypothesized the resources spent on caring for children are diluted [64]. In the case of birth interval, registration in Nigeria is a significant commitment for parents, and the longer the spacing between children, the less likely parents will make the commitment towards BC. Despite this, to draw any causal conclusions on the effects of birth order and birth interval on birth certification, more empirical work needs to be done to account for unobserved heterogeneities that may occur within-families. 
The findings from the random parts of the MLRM has shown a largely significant variance between communities and states even after adjusting for the characteristics at the child, parent, $\mathrm{HH}$ and community levels. It thus confirms the use of multilevel modeling techniques. This finding was consistent with the study conducted by [60], and justified by the existence of differences in coverage, social norms, cultural beliefs, geography, quality of health services and distribution of registration centers. One can thus conclude that $2.52 \%$ of the variation in $\mathrm{BC}$ is attributed to differences between states and $25.98 \%$ to differences between communities nested within the states.

\section{Strengths and Limitations}

To the best of my knowledge, this paper counts among the first studies highlighting the determinants of $\mathrm{BC}$ for Nigerian children. The wide range of variables employed in the analyses allows a true depiction of the SED characteristics associated with BC for children under-five years in Nigeria, and it is one of the few to carry out such large-scale investigation on the predictors of BC in the sub-Saharan African context. The study has numerous strengths. First, the study uses the NDHS data, the largest nationally representative and repeated cross-sectional data samples available for Nigeria. The pooled NDHS sample provides substantial heterogeneity within and between communities to analyze the association between the SED characteristics and BC. Given the comparable nature of the data, these findings could be tested in and generalized to other developing countries for whom data is available. Second, the study utilized different empirical methods including the multilevel logistic regression modeling to accommodate the hierarchical nature of the NDHS data and the binary nature of the outcome variable. The nested data structure corrects for bias on the parameter estimates as it explicitly models and uncovers heterogeneity in covariates effects [44]. Third, the pooled data and empirical techniques permit going beyond the analyses of [56] who used the BR variable which can 
be prone to bias when retrospective information is collection. The study also goes beyond the findings of [Error! Reference source not found., Error! Reference source not found., 62], who carried out small-scale studies on BR in Nigeria. Fourth, this study includes variables to measure geographical accessibility as one of the factors that can affect the child's BC status. According to [30], "accessibility to birth registration centers is influenced by the location, terrain, and infrastructure. The greater the distance to the registration center, the higher the financial and opportunity costs for the family, and the lower the likelihood of birth registration and certification." Previous attempts do not incorporate the supply-side constraints (e.g. distance to the nearest registration center) that may affect the probability of certification.

Despite the above strengths, the study has some limitations. First, the NDHS data is crosssectional which makes it difficult to track the children over time to confirm their certification status nor draw causal inference on the estimates. To verify the validity of the observed associations within the study and make causal claims, the SED variables (child vs. family vs. community) need to be unpacked by using longitudinal data or instrumental variable techniques. Second, the data does not precisely state whether the children were born in the location where they were surveyed. In the absence of information on migration, this is the basis exploited for the geographical variation to study the factors associated with birth registration. Further studies can incorporate the effect of internal migration on BC outcomes. Third, the data does not provide information on the exact timing of the registration. Hence, discussion on whether the child was registered on time is outside the scope of this study. It is important that future DHS studies include the age at birth registration to help improve the research by ascertaining the true impact of age on birth registration. Furthermore, the spatial data used to construct the accessibility to registration 
centers are de-identified to ensure confidentiality of the respondents. Future studies should employ longitudinal analysis to allow for a stronger generalization of the findings.

\section{Conclusion}

This study has provided significant insights into the role of socioeconomic and demographic factors on the birth certification status of children under-five years in a large sub-Saharan and middle-income country-Nigeria. Several SED characteristics were found to have significant influence on BC in Nigeria. The setting of Nigeria is particularly important for a study of this nature, as the country ranks high in child population, coupled with the high prevalence of poverty and low parental education (key measures of socioeconomic status). In addition to this, the inequality in land size across the nation also has interesting effects on the access to public facilities, which in turn has significant implications to the utilization of the public services. The results highlight the crucial roles played by health service utilization, socioeconomic status and accessibility to registration services. This information is extremely important to the government (e.g. the NPC), local and multinational organizations interested in improving birth registration and certification rates in Nigeria. To reduce the inequalities due to accessibility, it is important to increase the number of registration centers and reduce the distance parents must travel to register and certify their children's births. This would need strong political will and concerted efforts from the Nigerian government in the form of administrative support and funding systems. Additionally, the study findings suggest that children are less likely to have their births registered and certified as they near school going age (6 years). This goes against the mandate of the 2003 Child Rights Act. One way would be to integrate birth registration into schools or non-formal institutions (religious and community organizations), so that parents are aware of the process and benefits, or help mitigate distance-related barriers. I suggest the design and implementation of well targeted birth registration and health programs in order to ensure children are registered and certified on time. Ensuring this, 
will be valuable to achieving target of universal birth registration by 2030 . Another

suggestion is to ensure a holistic national child policy, which comprises all child

development factors - health, education and protection that are necessary to ensure that children survive and thrive in adulthood. Furthermore, to include children of poor and uneducated parents, free registration can be introduced to ensure that parents begin and complete the birth registration for the children, and on time too. Finally, for a comprehensive policy to be enacted, it is important that future studies conduct a causal investigation for each of the significant factors found in this study.

\section{List of abbreviations}

BC: Birth Certification; BR: Birth registration; DIC: Deviance Information Criterion; HH: Household; ICC: Intraclass Correlation Coefficient; MCMC: Markov Chain Monte Carlo; MLRM: Multilevel Logistic Regression Model; MOR: Median Odds Ratio; NC: NorthCentral; NDHS; Nigerian Demographic \& Health Survey; NE: North-East; NPC: National Population Commission; NW: North-West; OLS: Ordinary Least Squares; OR: Odds Ratio; PCV: Proportional Change in Variance; PQL: Penalized Quasi Likelihood; RE: Random Effects; SBA: Skilled Birth Attendant; SDG: Sustainable Development Goals; SE: SouthEast; SED: Socioeconomic and Demographic; SS: South-South; SW: South-West; UNCRC: United Nations Convention on the Rights of the Child.

\section{Declarations}

\section{Ethics approval and consent to participate}

The author was granted approval from the DHS Review Board, ORC Macro Inc to obtain and use the collected data for analysis. All the respondent identifiers were removed prior to the author downloading and using the data.

\section{Consent for publication}

Not applicable

\section{Availability of data and materials}

The dataset analyzed during the current study are available in the DHS data repository, https://www.dhsprogram.com/data/dataset_admin/index.cfm.

\section{Competing interests}

The author declares no competing interests.

\section{Funding}

The research presented in this study was part of a doctoral research program in Lingnan University funded by the Research Grants Council (RGC) of the Hong Kong PhD Fellowship Scheme 2016 [grant number PF15-11891]. The RGC provided monthly stipends which enabled me study in the Department of Economics. They played no role in the design of the study and collection, analysis, and interpretation of data and in writing the final manuscript. 


\section{Authors' contribution}

USA analyzed and interpreted the data. USA also read and approved the final manuscript.

\section{Acknowledgments}

I acknowledge the MEASURE-DHS program who made the data publicly available for noncommercial use. I also thank the doctoral research supervisors, Professor LIN Ping and Associate Professor WONG Ho Lun (Alex) of Lingnan University for their useful comments and suggestions during the development and completion of the research project. I also thank all those who contributed in one way or another in getting the article published.

\section{References}

1. United Nations Children's Fund. Strengthening birth registration in Africa: Opportunities and partnerships. New York: United Nations Children's Fund; 2010. Retrieved from https://www.unicef.org/esaro/Technical_paper_low_res_pdf

2. United Nations Children's Fund. The 'Rights' Start to Life: Statistical Analysis of Birth Registration. New York: United Nations Children's Fund; 2005. Retrieved from https://www.unicef.org/protection/BirthReg10a_rev.pdf.

3. Jeong J, Bhatia A, \& Fink G. Associations between birth registration and early child growth and development: Evidence from 31 low- and middle-income countries. BMC Public Health. 2018; 18(673):1-8. DOI: 10.1186/s12889-018-5598-z.

4. United Nations Children's Fund. Briefing note No. 15. New York: United Nations Children's Fund; 2015. Retrieved from https:// data.unicef.org/SDG-briefing-note15 birth-registration. Accessed 22 January 2019.

5. Duff $P$, Kusumaningrum $S, \&$ Stark L. Barriers to birth registration in Indonesia [Correspondence]. The Lancet. 2016;4:e234-e235. Retrieved from: from https://doi.org/ 10.1016/S2214-109X(15)00321-6. Accessed $10 \mathrm{Jul} 2018$.

6. Setel PW, Macfarlane SB, Szreter, S, Mikkelsen L, Jha P, Stout S, \& AbouZahr C. A scandal of invisibility: making everyone count by counting everyone. The Lancet. 2007. Retrieved from https://doi.org/ 10.1016/S0140-6736(07)61307-5. Accessed 22 Jan 2019.

7. Setel PW, Macfarlane SB, Szreter S, Mikkelsen L, Jha P, Stout S, \& AbouZahr C. Who Counts? 1. The Lancet. 2007. Retrieved from https://www.who.int/ health info/statistics/WhoCounts1.pdf. Accessed 22 Jan 2019.

8. United Nations Children's Fund. Every child's birthright: Inequities and trends in birth registration. New York: United Nations Children's Fund; 2013. Retrieved from https: // www.un.org/ruleoflaw/files/Embargoed_11_Dec_Birth_Registration_report_low res.pdf. Accessed 9 July 2018.

9. Garenne M, Collinson MA, Kabudula CW, Gomez-Olive FX, Kahn K, \& Tollman S. Improving completeness of birth and death registration in rural Africa. The Lancet. Global Health. 2016;4(9):e604-5. Retrieved from https://doi.org/10.1016/S2214109X(16)30146-2.

10. Garenne M, Collinson MA, Kabudula CW, Gomez-Olive FX, Kahn K, \& Tollman S. Completeness of birth and death registration in a rural area of South Africa: the Agincourt health and demographic surveillance, 1992-2014. Global Health Action. 2016:9(1):32795. https://doi.org/10.3402/gha.v9.32795.

11. Giang KB, Oh J, Kien VD, Hoat LN, Choi S, Lee CO, \& Minh HV. Changes and inequalities in early birth registration and childhood care and education in Vietnam: findings from the Multiple Indicator Cluster Surveys, 2006 and 2011. [Special Issue: 
Millennium Development Goals in Vietnam: the Progress and Social Determinants]. Global Health Action. 2016;9(1). https://doi.org/10.1016/10.3402/gha.v9.29470.

12. Szreter S. The right of registration: Development, identity registration, and social security - a historical perspective. World Development. 2006;35(1). https://doi.org/10.1016/10.1016/j.worlddev.2006.09.004.

13. United Nations Children's Fund - Innocenti Research Centre (2002). Birth Registration (Tech. Rep. No. 9). UNICEF Innocenti Research Centre. Florence: United Nations Children's Fund - Innocenti Research Centre; 2002. Retrieved from https://www.unicef -irc.org/publications/pdf/digest9e.pdf. Accessed 10 Feb 2019.

14. Hunter W. Identity Documents, Welfare Enhancement, and Group Empowerment in the Global South. The Journal of Development Studies. 2019;155:366-83. https://doi.org/10.1080/00220388.2018.1451637.

15. Phillips DE, Adair T, \& Lopez AD. How useful are registered birth statistics for health and social policy? A global systematic assessment of the availability and quality of birth registration data. Population Health Metrics. 2018;16(21):1-13. https://doi.org/ 10.1186/ s12963-018-0180-6.

16. AbouZahr C, de Savigny D, Mikkelsen L, Phillip WS, Lozano R, Nichols E, Notzon F, Lopez AD. Civil registration and vital statistics: progress in the data revolution for counting and accountability [Series]. The Lancet. 2015;386:1373-1385. http://dx.doi.org/10.1016/S0140-6736(15)60173-8.

17. Brito S, Corbacho A, \& Osorio R. Birth Registration: The Key to Social Inclusion in Latin America and the Caribbean (Report). Inter-American Development Bank; 2003. Retrieved from https://publications.iadb.org/publications/ english/document/BirthRegistration-The-Key-to-Social-Inclusion-in-Latin-America-and-the-Caribbean.pdf.

18. National Population Commission - NPC/Nigeria and ICF. Nigeria Demographic and Health Survey 2018 [Dataset]. NPC and ICF. Abuja, Nigeria, and Rockville, Maryland, USA: National Population Commission and ICF International, Inc; 2008-2018.

19. Wilson M. Mapping Access to Birth Registration and Updates from Tanzania. GSM Association (GSMA); 2017. Retrieved from https://www.gsma.com/mobilefor development/programme/digital-identity/mapping-access-birth-registration-updatestanzania. Accessed 18 Aug 2018.

20. Makinde OA, Olapeju B, Ogbuoji O, \& Babalola S. Trends in the completeness of birth registration in Nigeria: 2002-2010. Journal of Demographic Research. 2016;35(12), 315-338. Retrieved from https://doi.org/10.1016/10.4054/DemRes.2016.35.12.

21. Isara $\mathrm{AR}, \&$ Atimati $\mathrm{AO}$. Socio-demographic determinants of birth registration among mothers in an urban community in southern Nigeria. Journal of Medicine in the Tropics. 2015;17(1):16-21. Retrieved from http://www.jmedtropics.org/temp/JMed Trop17116-3505407_094414.pdf. Accessed 23 November 2018.

22. Jackson M, Duff P, Kusumanigrum S, \& Stark L. Thriving beyond survival: Understanding utilization of perinatal health services as predictors of birth registration: A cross-sectional study. BMC International Health and Human Rights. 2014;14(306). DOI: $10.1186 / \mathrm{s} 12914-014-0038-3$.

23. Dake FAA, \& Fuseini K. Registered or unregistered? levels and differentials in registration and certification of births in Ghana. BMC International Health and Human Rights. 2018;18(25). Retrieved from https://bmcinthealthhumrights .biomedcentral.com/articles/10.1186/s12914-018-0163-5. Accessed 26 July 2018.

24. Gibberd AJ, Simpson JM, \& Eades SJ. No official identity: a data linkage study of birth registration of Aboriginal children in Western Australia. Australian and New Zealand Journal of Public Health. 2016;40(4):388-394. Retrieved from https://doi.org/10.1111/1753-6405.12548. Accessed 9 Nov 2018. 
25. Duryea S, Olgiati A, \& Stone L. The Under-Registration of Births in Latin America (Working Paper No. 551). Washington, DC: Inter-American Development Bank; 2006. Retrieved from https://www.econstor.eu/bitstream/10419/88088/1/idb-wp_551.pdf.

26. Adi AE, Abdu T, Amir K, Rashid, MH, Ebri, UE, Cockcroft A, \& Andersson, N. Understanding whose births get registered: a cross-sectional study in Bauchi and Cross River states, Nigeria. BMC Research Notes. 2015;8(79). https://doi.org/10.1186/s13104-015-1026-y.

27. Butt L, \& Ball J. Strategic actions of transnational migrant parents regarding birth registration for stay-behind children in Lombok, Indonesia: Birth registration and staybehind children. Population, Space and Place. 2018;25(1):e2152. Retrieved from https://doi.org/10.1002/psp.2152.

28. Amo-Adjei J, \& Annim SK. Socio-Economic determinants of birth registration in Ghana. BMC International Health and Human Rights. 2015;15(14):1-9. DOI: https://dx.doi.org/10.1186\%2Fs12914-015-0053-Z. Accessed 22 Jun 2018

29. Corbacho A, Brito S, \& Osorio Rivas R. Birth registration and the impact on educational attainment. In (p. 1-31). Inter-American Development Bank; 2012 Retrieved from https://www.dartmouth.edu/neudc2012/docs/paper_109.pdf. Accessed 15 Sep 2018.

30. Corbacho A, \& Osorio Rivas R. Travelling the distance: A GPS-based study of the access to birth registration services in Latin America and the Caribbean. IDB Working Paper Series IDB-WP-307. 2012. Retrieved from http://hdl.handle.net/10419/88998. Accessed 12 Aug 2018.

31. National Population Commission - NPC/Nigeria and ICF. Nigeria Demographic and Health Survey 2018 (Final Report No. FR359). NPC and ICF. Abuja, Nigeria, and Rockville, Maryland, USA: National Population Commission and ICF International, Inc; 2019. Retrieved from https://dhsprogram.com/pubs/pdf/FR359/FR359.pdf.

32. Althubaiti A. Information bias in health research: definition, pitfalls, and adjustment methods. Journal of Multidisciplinary Healthcare. 2016;9:211-217. https://doi.org/10.2147/JMDH.S104807.

33. Mosley, WH, \& Chen, L. C. An Analytical Framework for the Study of Child Survival in Developing Countries. Population and Development Review. 1984;10:25-45. https://doi.org/10.2307/2807954.

34. McGovern, ME. How much does Birth Weight Matter for Child Health in Developing Countries? (Working Paper). 2016. Retrieved from https://scholar.harvard.edu/ files/mcgovern/files/mark_mcgovern/birth_weight_may.pdf. Accessed 9 Dec 2017.

35. Filmer D, \& Pritchett LH. Estimating Wealth Effects without Expenditure Data-or Tears: An Application to Educational Enrollments in States of India. Demography. 2001;38(1):115-132. Retrieved from https://www.ncbi.nlm.nih.gov/pubmed/11227840. Accessed 13 Jun 2018.

36. Filmer D, \& Scott K. Assessing asset indices. Demography. 2012;49:359-392. https://doi.org/10.1007/s13524-011-0077-5.

37. Antai D. Inequitable childhood immunization uptake in Nigeria: a multilevel analysis of individual and contextual determinants. BMC Infectious Diseases. 2009;9(181);110. Retrieved from: http://www.biomedcentral.com/1471-2334/9/181.

38. Rutstein S, \& Johnson K. The DHS Wealth Index (DHS Comparative Reports No. 6). 2004. Retrieved from: https://dhsprogram.com/publications/ publication-cr6comparative-reports.cfm. Accessed 23 Jan 2017.

39. Merlo J, Yang M, Chaix B, Lynch J, \& Rastam L. A brief conceptual tutorial on multilevel analysis in social epidemiology: investigating contextual phenomena in 
different groups of people. Journal of Epidemiology \& Community Health. 2005;59(9): 729-736. http://doi.org/10.1136/ jech.2004.023929.

40. Smith T, \& Shively G. Multilevel analysis of individual, household, and community factors influencing child growth in Nepal. BMC Pediatrics. 2019;19(91):1-14. https://doi.org/ 10.1186/s12887-019-1469-8.

41. Merlo J, Chaix B, Ohlsson H, Beckman A, Johnell K, Hjerpe P, Rastam L, Larsen K. A brief conceptual tutorial of multilevel analysis in social epidemiology: using measures of clustering in multilevel logistic regression to investigate contextual phenomena. Journal of Epidemiology and Community Health. 2006;60:290-297. http://dx.doi.org /10.1136/jech.2004.029.454.

42. Snijders TAB, \& Bosker RJ. Multilevel Analysis: An Introduction to Basic and Advanced Multilevel Modeling. 2nd ed. Sage Publishers; 2012.

43. Fahrmeir L, Kneib T, Lang S, \& Marx B. Regression: Models, methods and applications. Springer-Verlag; 2013.

44. Harttgen K, Lang S, \& Santer J. Multilevel modelling of child mortality in Africa (Working Papers in Economics and Statistics No. 2015-03). University of Innsbruck; 2015. Retrieved from https://www2.uibk.ac.at/downloads/ c4041030/wpaper/201503.pdf. Accessed 22 Jan 2020.

45. Spiegelhalter DJ, Best NG, Carlin BP, \& van der Linde A. Bayesian measures of model complexity and fit. Journal of the Royal Statistical Society. 2002;64:583-639.

46. StataCorp. Stata Statistical Software: Release 14. College Station, TX: StataCorp LP; 2015.

47. Browne WJ. (2019). MCMC Estimation in MLwiN v3.03 [Computer software] Centre for Multilevel Modelling, University of Bristol, UK.

48. Charlton C, Rasbash J, Browne WJ, Healy M, \& Cameron B. (2019). MLwiN Version 3.04. Centre for Multilevel Modelling, University of Bristol, UK.

49. Archibong B. Essays on the impacts of geography and institutions on access to energy and public infrastructure services (Ph.D. thesis, Columbia University, New York, USA). 2015. Retrieved from https://academiccommons.columbia.edu/catalog/ac: 186998.

50. Babalola S, \& Oyenubi O. Factors explaining the North-South differentials in contraceptive use in Nigeria: A nonlinear decomposition analysis. Demographic Research. 2018;38(12):287-308. Retrieved from https://www.demographicresearch.org/Volumes/Vol38/12/ DOI: 10.4054/DemRes.2018.38.12. Accessed 13 Jun 2018.

51. Ecker O, Hatzenbuehler PL, \& Mahrt K. Transforming Agriculture for Improving Food and Nutrition Security among Nigerian Farm Households (Working Paper No. 56).

Washington, DC: IFPRI; 2018. Retrieved from https://www.ifpri.org/publication/transforming-agriculture-improving-food-andnutrition-security-among-nigerian-farm.

52. Roser M. Fertility rate. Our World in Data. 2020. Retrieved from https://ourworldin data.org/fertility-rate

53. Cunha F, \& Heckman, JJ. The Technology of Skill Formation. American Economic Review. 2007;97(2):31-47. https://doi.org/10.1257/aer.97.2.31

54. Guryan J, Hurst E, \& Kearney M. Parental Education and Parental Time with Children. Journal of Economic Perspectives. 2008;22(3):23-46. https://doi.org/10.1257/ jep.22.3.23.

55. Andrew EV, Pell C, Angwin A, Auwun, A, Daniels J, Mueller I, Phuanukoonnon S, Pool R. Factors affecting attendance at and timing of formal antenatal care: Results 
from a qualitative study in Madang, Papua New Guinea. PLoS ONE. 2014;9(5):e93025. https://doi.org/10.1371/journal.pone.0093025.

56. Kandala N, Madungu TP, Emina JBO, Nzita KPD, \& Cappuccio FP. Malnutrition among children under the age of five in the Democratic Republic of Congo (DRC): does geographic location matter? BMC Public Health. 2011;11:261. http://www.biomedcentral.com/1471-2458/11/261

57. Fall CHD, Sachdev HS, Osmond C, Restrepo-Mendez MC, Victora C, Martorell R, Stein AD, Sinha S, Tandon N, Adair L, Bas I, Norris S, \& Richter LM. Association between maternal age at childbirth and child and adult outcomes in the offspring: a prospective study in five low-income and middle-income countries (COHORTS collaboration). Lancet Global Health. 2015 Jul;3(7):e341-e422. https://doi.org/10.1016/S2215-109X(15)00038-8.

58. Hyuncheol BK, Choi S, Kim B, \& Pop-Eleches C. The role of education interventions in improving economic rationality. Science. 2018;362(6410):83. https://doi.org/10.1126/science.aar6987.

59. Arthi V, \& Fenske J. Polygamy and child mortality: Historical and modern evidence from Nigeria's Igbo. Review of Economics of the Household. 2018;16:97-14. Retrieved from https://doi.org/10.1007/s11150-016-9353-x.

60. Garenne M, Collinson MA, Kabudula CW, Gomez-Olive FX, Kahn K, \& Tollman S. Completeness of birth and death registration in a rural area of South Africa: the Agincourt health and demographic surveillance, 1992-2014. Global Health Action. 2016;9:1:32795. https://doi.org/10.3402/gha.v9.32795Okunlola OA, Olapade EO, Mathenge GW, \& Folorunso SA. Multilevel Analysis on the Determinants of Birth Registration in Nigeria. Science and Technology Publishing (SCI \& TECH). 2017:1:8. Retrieved from https://www.researchgate.net/publication/319352552_Multilevel_Analysis_On_The_D eterminants_Of_Birth_Registration_In_Nigeria.

61. Tobin EA, Obi AI, \& Isah EC. Status of birth and death registration and associated factors in the South-South region of Nigeria. Annals of Nigerian Medicine. 2013;7:1-5. Retrieved from https://doi.org/10.4103/0331-3131.119979.

62. Mohanty I, \& Gebremedhin TA. Maternal autonomy and birth registration in India: Who gets counted? PLoS ONE. 2018;13(3);1-20. Retrieved from https://doi.org/ 10.1371/journal.pone.0194095.

63. Cappa C., Gregson K., Wardlaw T., \& Bissell S. Birth registration: a child's passport to protection. The Lancet. Global Health. 2013;2(2):PE67-E68. http://dx.doi.org/ 10.1016/S2214-109X(13)70180-3.

64. Linder PH. Sibling position and achievement. Journal of Human Resources. 1977;12:198-219. 
Table 1 Mean birth certification rates and ranking by regions and states in Nigeria

\begin{tabular}{|c|c|c|c|c|c|c|}
\hline Region & $\begin{array}{c}\text { Mean } \\
(\%)\end{array}$ & $\begin{array}{c}\text { Region } \\
\text { rank }\end{array}$ & State & $\begin{array}{c}\text { Mean } \\
(\%)\end{array}$ & $\begin{array}{l}\text { State } \\
\text { rank }\end{array}$ & $\begin{array}{l}\text { State mean compared } \\
\text { to regional mean }\end{array}$ \\
\hline South-West & 26.84 & 1 & Oyo & 33.43 & 1 & Higher \\
\hline North-Central & 13.72 & 4 & $\mathrm{FCT}^{2}$ & 33.04 & 2 & Higher \\
\hline North-West & 13.17 & 5 & Katsina & 29.59 & 3 & Higher \\
\hline South-East & 19.96 & 2 & Anambra & 29.17 & 4 & Higher \\
\hline South-West & 26.84 & 1 & Lagos & 27.83 & 5 & Higher \\
\hline South-West & 26.84 & 1 & Ekiti & 27.07 & 6 & Higher \\
\hline South-West & 26.84 & 1 & Osun & 24.64 & 7 & Lower \\
\hline South-South & 17.47 & 3 & Edo & 23.74 & 8 & Higher \\
\hline North-Central & 13.72 & 4 & Nasarawa & 21.49 & 9 & Higher \\
\hline South-West & 26.84 & 1 & Ondo & 20.96 & 10 & Lower \\
\hline North-East & 11.91 & 6 & Adamawa & 20.82 & 11 & Higher \\
\hline South-West & 26.84 & 1 & Ogun & 20.57 & 12 & Lower \\
\hline South-South & 17.47 & 3 & Delta & 19.68 & 13 & Higher \\
\hline North-Central & 13.72 & 4 & Kwara & 19.45 & 14 & Higher \\
\hline South-South & 17.47 & 3 & Rivers & 19.36 & 15 & Higher \\
\hline North-West & 13.17 & 5 & Kaduna & 19.03 & 16 & Higher \\
\hline South-East & 19.96 & 2 & Imo & 18.93 & 17 & Lower \\
\hline South-East & 19.96 & 2 & Abia & 17.03 & 18 & Lower \\
\hline South-South & 17.47 & 3 & Akwa_Ibom & 16.97 & 19 & Lower \\
\hline South-East & 19.96 & 2 & Ebonyi & 16.92 & 20 & Lower \\
\hline North-Central & 13.72 & 4 & Kogi & 16.06 & 21 & Higher \\
\hline North-East & 11.91 & 6 & Gombe & 13.26 & 22 & Higher \\
\hline North-East & 11.91 & 6 & Taraba & 12.33 & 23 & Higher \\
\hline South-East & 19.96 & 2 & Enugu & 12.26 & 24 & Lower \\
\hline North-East & 11.91 & 6 & Borno & 12.14 & 25 & Higher \\
\hline North-Central & 13.72 & 4 & Benue & 11.88 & 26 & Lower \\
\hline North-West & 13.17 & 5 & Kano & 11.65 & 27 & Lower \\
\hline South-South & 17.47 & 3 & Cross_River & 11.61 & 28 & Lower \\
\hline North-West & 13.17 & 5 & Jigawa & 9.13 & 29 & Lower \\
\hline North-East & 11.91 & 6 & Yobe & 9.01 & 30 & Lower \\
\hline North-Central & 13.72 & 4 & Plateau & 8.84 & 31 & Lower \\
\hline North-East & 11.91 & 6 & Bauchi & 7.99 & 32 & Lower \\
\hline North-Central & 13.72 & 4 & Niger & 7.66 & 33 & Lower \\
\hline South-South & 17.47 & 3 & Bayelsa & 6.81 & 34 & Lower \\
\hline North-West & 13.17 & 5 & Kebbi & 5.82 & 35 & Lower \\
\hline North-West & 13.17 & 5 & Sokoto & 2.94 & 36 & Lower \\
\hline North-West & 13.17 & 5 & Zamfara & 2.10 & 37 & Lower \\
\hline NATIONAL & 16.14 & & & & & \\
\hline
\end{tabular}


Table 2 Participant characteristics $(\mathrm{N}=79,487)$.

\begin{tabular}{|c|c|c|c|}
\hline & Mean $^{\mathrm{a}}$ & SD & Group Diff. $(\beta)^{b}$ \\
\hline \multicolumn{4}{|l|}{ Personal characteristics } \\
\hline Male $(0 / 1)$ & 0.51 & 0.50 & -0.00 \\
\hline Child is multiple $(0 /)$ & 0.01 & 0.12 & -0.00 \\
\hline Age (ref: $<12$ months) & 0.22 & 0.42 & $0.01 *$ \\
\hline $12-23$ & 0.20 & 0.40 & $-0.01 *$ \\
\hline $24-35$ & 0.19 & 0.39 & $-0.01 *$ \\
\hline $36-47$ & 0.20 & 0.40 & $-0.01 *$ \\
\hline $48-59$ & 0.19 & 0.39 & $0.02 * * *$ \\
\hline Birth order (ref: 1st) & 0.18 & 0.38 & $-0.03 * * *$ \\
\hline $2^{\text {nd }}$ & 0.18 & 0.38 & $-0.04 * * *$ \\
\hline $3^{\text {rd }}$ & 0.16 & 0.36 & $-0.01 * *$ \\
\hline $4^{\text {th }}$ & 0.49 & 0.50 & $0.08 * * *$ \\
\hline Size-at-birth (ref: Small) & 0.14 & 0.34 & $0.04 * * *$ \\
\hline Average & 0.44 & 0.50 & $0.03 * * *$ \\
\hline Large & 0.43 & 0.49 & $-0.08 * * *$ \\
\hline Birth Interval (year) & 2.86 & 1.81 & $0.07 * *$ \\
\hline $\operatorname{SBA}(0 / 1)$ & 0.36 & 0.48 & $-0.26 * * *$ \\
\hline Vaccination $(0 / 1)$ & 0.63 & 0.48 & $-0.24 * * *$ \\
\hline \multicolumn{4}{|l|}{ Maternal Characteristics } \\
\hline Age $(<20$ years $)$ & 0.11 & 0.31 & $0.04 * * *$ \\
\hline $20-24$ & 0.25 & 0.43 & $0.01 * *$ \\
\hline $25-29$ & 0.27 & 0.45 & $-0.04 * * *$ \\
\hline $30-34$ & 0.19 & 0.40 & $-0.03 * * *$ \\
\hline $35+$ & 0.17 & 0.38 & $0.01 *$ \\
\hline Mother's marital status (ref: In a union) & 0.98 & 0.15 & $-0.01 * * *$ \\
\hline Separated & 0.01 & 0.08 & $0.00 * * *$ \\
\hline Divorced & 0.01 & 0.08 & $0.00 *$ \\
\hline Education (years) & 4.92 & 5.36 & $-3.16 * * *$ \\
\hline Prenatal visits $(0 / 1)$ & 0.73 & 0.44 & $-0.18 * * *$ \\
\hline Polygynous $(0 / 1)$ & 0.33 & 0.47 & $0.09 * * *$ \\
\hline Occupation (ref: Other) & 0.36 & 0.48 & $0.10 * * *$ \\
\hline Low skill & 0.10 & 0.30 & $0.02 * * *$ \\
\hline Medium skill & 0.50 & 0.50 & $-0.08 * * *$ \\
\hline High skill & 0.04 & 0.20 & $-0.04 * * *$ \\
\hline Decision-maker $(0 / 1)$ & 0.57 & 0.50 & $-0.10 * * *$ \\
\hline Access to media $(0 / 1)$ & 0.58 & 0.49 & $-0.18 * * *$ \\
\hline Lost $2+$ children $(0 / 1)$ & 0.15 & 0.35 & $0.07 * * *$ \\
\hline \multicolumn{4}{|l|}{ Paternal Characteristics } \\
\hline Age $(<25$ years $)$ & 0.02 & 0.13 & $0.01 * * *$ \\
\hline $25-34$ & 0.27 & 0.44 & 0.00 \\
\hline $35-44$ & 0.40 & 0.49 & $-0.05^{* *}$ \\
\hline $45-54$ & 0.24 & 0.42 & $0.02 * * *$ \\
\hline
\end{tabular}


Table 2 Participant characteristics $(\mathrm{N}=79,487)$ (Continued)

\begin{tabular}{|c|c|c|c|}
\hline $55+$ & 0.08 & 0.28 & $0.02 * * *$ \\
\hline Education (years) & 6.54 & 5.81 & $-3.11 * * *$ \\
\hline Occupation (ref: Other) & 0.03 & 0.17 & $0.01 * * *$ \\
\hline Low skill & 0.46 & 0.50 & $0.24 * * *$ \\
\hline Medium skill & 0.40 & 0.49 & $-0.17 * * *$ \\
\hline High skill & 0.10 & 0.31 & $-0.09 * * *$ \\
\hline \multicolumn{4}{|l|}{ Household characteristics } \\
\hline Owns a bank account $(0 / 1)$ & 0.35 & 0.48 & $-0.22 * * *$ \\
\hline Wealth (ref: Poor) & 0.47 & 0.50 & $0.29 * * *$ \\
\hline Average & 0.20 & 0.40 & $0.02 * * *$ \\
\hline Rich & 0.33 & 0.47 & $-0.31 * * *$ \\
\hline Religion (ref: Islam) & 0.59 & 0.49 & $0.14 * * *$ \\
\hline Christian & 0.40 & 0.49 & $-0.14 * * *$ \\
\hline Other & 0.02 & 0.13 & $0.01 * * *$ \\
\hline Ethnicity (ref: Hausa/Fulani) & 0.40 & 0.49 & $0.15^{* * *}$ \\
\hline Igbo & 0.12 & 0.32 & $-0.06 * * *$ \\
\hline Yoruba & 0.11 & 0.31 & $-0.10 * * *$ \\
\hline Other & 0.38 & 0.48 & $0.10 *$ \\
\hline \multicolumn{4}{|l|}{ Community Characteristics } \\
\hline Rural (ref: Urban) & 0.67 & 0.47 & $0.25 * * *$ \\
\hline Dist. to registration centers (ref: $<5 \mathrm{kms}$ ) & 0.46 & 0.50 & $-0.24 * * *$ \\
\hline $5-9.99 \mathrm{kms}$ & 0.25 & 0.43 & $0.08 * * *$ \\
\hline $10+\mathrm{kms}$ & 0.29 & 0.45 & $0.16^{* * *}$ \\
\hline Distance to Roads (ref: $<5 \mathrm{kms}$ ) & 0.17 & 0.38 & $-0.04 * * *$ \\
\hline $5-9.99 \mathrm{kms}$ & 0.11 & 0.32 & $-0.04 * * *$ \\
\hline $10+\mathrm{kms}$ & 0.71 & 0.45 & $0.08 * * *$ \\
\hline Altitude (ref: Low) & 0.49 & 0.50 & $-0.05 * * *$ \\
\hline Medium & 0.23 & 0.42 & $0.03 * * *$ \\
\hline High & 0.28 & 0.45 & $0.03 * * *$ \\
\hline Female education & 4.95 & 4.28 & $-2.49 * * *$ \\
\hline Male education & 6.49 & 4.19 & $-2.40 * * *$ \\
\hline$\%$ Poor HHs & 0.47 & 0.41 & $0.27 * * *$ \\
\hline Child mortality & 0.58 & 0.42 & $0.16^{* * *}$ \\
\hline Region (ref: SW) & 0.12 & 0.32 & $-0.09 * * *$ \\
\hline $\mathrm{NC}$ & 0.17 & 0.37 & -0.01 \\
\hline $\mathrm{NE}$ & 0.22 & 0.41 & $0.04 * * *$ \\
\hline NW & 0.30 & 0.46 & $0.12 * * *$ \\
\hline SE & 0.10 & 0.30 & $-0.04 * * *$ \\
\hline SS & 0.11 & 0.31 & $-0.02 * * *$ \\
\hline
\end{tabular}

Note: ${ }^{\mathrm{a}}$ This represents a proportion for categorical variables. ${ }^{\mathrm{b}}$ Beta values for the two-sample meancomparison tests (ttest) between the certified and non-certified groups. A negative (positive) sign implies that non-certified children are less (more) likely to have a lower (higher) mean or proportion for that category. $* \mathrm{p}<0.10, * * \mathrm{p}<0.05, * * * \mathrm{p}<0.01$. 
Table 3 Predictors of birth certification

\begin{tabular}{|c|c|c|c|c|c|c|}
\hline & \multicolumn{2}{|r|}{ Model 1a } & \multicolumn{2}{|r|}{ Model 2b } & \multicolumn{2}{|r|}{ Model 3c } \\
\hline & OR & $95 \% \mathrm{CI}$ & OR & $95 \% \mathrm{CI}$ & OR & $95 \% \mathrm{CI}$ \\
\hline Constant & 0.136 & $(0.091-0.187)^{* * *}$ & 0.042 & $(0.022-0.077) * * *$ & 0.050 & $(0.029-0.080) * * *$ \\
\hline \multicolumn{7}{|c|}{$\begin{array}{l}\text { Personal characteristics } \\
\text { Age (ref: < } 12 \text { months) }\end{array}$} \\
\hline $12-23$ & 0.953 & $(0.833-1.075)$ & 0.913 & $(0.811-1.028)^{*}$ & 0.931 & $(0.822-1.065)$ \\
\hline $24-35$ & 0.914 & $(0.745-1.088)$ & 0.820 & $(0.694-0.984)^{* *}$ & 0.850 & $(0.696-1.040)^{*}$ \\
\hline $36-47$ & 0.939 & $(0.736-1.179)$ & 0.781 & $(0.640-0.996)^{* *}$ & 0.824 & $(0.636-1.058)^{*}$ \\
\hline $48-59$ & 0.700 & $(0.530-0.921)^{* *}$ & 0.546 & $(0.431-0.729) * * *$ & 0.584 & $(0.439-0.781)^{* * *}$ \\
\hline \multicolumn{7}{|c|}{ Birth order (ref: 1st) } \\
\hline $2^{\text {nd }}$ & 1.011 & $(0.928-1.101)$ & 0.987 & $(0.904-1.076)$ & 0.990 & $(0.901-1.080)$ \\
\hline $3^{\text {rd }}$ & 0.972 & $(0.892-1.060)$ & 0.951 & $(0.863-1.044)$ & 0.955 & $(0.861-1.048)$ \\
\hline $4^{\text {th }}$ & 0.871 & $(0.805-0.940) * * *$ & 0.931 & $(0.841-1.027)^{*}$ & 0.935 & $(0.830-1.040)^{*}$ \\
\hline \multicolumn{7}{|c|}{ Size-at-birth (ref: Small) } \\
\hline Average & 1.019 & $(0.975-1.062)$ & 1.014 & $(0.971-1.056)$ & 1.013 & $(0.971-1.057)$ \\
\hline Large & 1.114 & $(1.069-1.157)^{* * *}$ & 1.082 & $(1.038-1.125)^{* * *}$ & 1.083 & $(1.037-1.129)^{* * *}$ \\
\hline $\begin{array}{l}\text { Birth Interval } \\
\text { (months) }\end{array}$ & 0.980 & $(0.966-0.995)^{* *}$ & 0.981 & $(0.965-0.996)^{* * *}$ & 0.982 & $(0.967-0.998)^{* *}$ \\
\hline $\operatorname{SBA}(0 / 1)$ & 1.690 & $(1.570-1.804)^{* * *}$ & 1.272 & $(1.184-1.366)^{* * *}$ & 1.256 & $(1.162-1.359)^{* * *}$ \\
\hline Vaccination $(0 / 1)$ & 1.863 & $(1.713-2.023)^{* * *}$ & 1.603 & $(1.463-1.740) * * *$ & 1.605 & $(1.469-1.742)^{* * *}$ \\
\hline \multicolumn{7}{|c|}{ Maternal Characteristics } \\
\hline \multicolumn{7}{|c|}{ Age (ref: $<20$ years) } \\
\hline $20-24$ & & & 1.112 & $(0.997-1.247)^{* *}$ & 1.087 & $(0.958-1.241)^{*}$ \\
\hline $25-29$ & & & 1.190 & $(1.047-1.358)^{* * *}$ & 1.152 & $(0.999-1.349)^{* *}$ \\
\hline $30-34$ & & & 1.202 & $(1.037-1.399) * * *$ & 1.167 & $(0.999-1.391)^{* *}$ \\
\hline $35+$ & & & 1.186 & $(1.007-1.391)^{* *}$ & 1.143 & $(0.960-1.385)^{*}$ \\
\hline \multicolumn{7}{|c|}{ Mother's marital status (ref: In a union) } \\
\hline Separated & & & 0.482 & $(0.297-0.709) * * *$ & 0.471 & $(0.310-0.691)^{* * *}$ \\
\hline Divorced & & & 0.675 & $(0.443-0.965)^{* *}$ & 0.646 & $(0.426-0.910) * * *$ \\
\hline Education (years) & & & 1.022 & $(1.014-1.031)^{* * *}$ & 1.023 & $(1.014-1.031)^{* * *}$ \\
\hline $\begin{array}{l}\text { Had 1+ Prenatal } \\
\text { visit }(0 / 1)\end{array}$ & & & 1.384 & $(1.257-1.518) * * *$ & 1.350 & $(1.221-1.487)^{* * *}$ \\
\hline Polygynous (0/1) & & & 0.930 & $(0.862-1.001)^{* *}$ & 0.943 & $(0.873-1.015)^{*}$ \\
\hline $\begin{array}{l}\text { Lost } 2+\text { children } \\
(0 / 1)\end{array}$ & & & 0.812 & $(0.732-0.894)^{* * *}$ & 0.826 & $(0.747-0.914)^{* * *}$ \\
\hline \multicolumn{7}{|c|}{ Paternal Characteristics } \\
\hline \multicolumn{7}{|c|}{ Father's age (ref: $<25$ years) } \\
\hline $25-34$ & & & 1.155 & $(0.940-1.506)^{*}$ & 1.239 & $(0.904-1.587)^{*}$ \\
\hline $35-44$ & & & 1.213 & $(0.975-1.584)^{*}$ & 1.298 & $(0.948-1.672)^{*}$ \\
\hline $45-54$ & & & 1.180 & $(0.939-1.589)^{*}$ & 1.261 & $(0.896-1.646)^{*}$ \\
\hline $55+$ & & & 1.191 & $(0.930-1.607)^{*}$ & 1.250 & $(0.879-1.647)^{*}$ \\
\hline Education (years) & & & 1.013 & $(1.006-1.021)^{* * *}$ & 1.012 & $(1.004-1.020)^{* * *}$ \\
\hline \multicolumn{7}{|c|}{ Occupation (ref: Other) } \\
\hline Low skill & & & 0.859 & $(0.802-0.918) * * *$ & 0.882 & $(0.818-0.948)^{* * *}$ \\
\hline Medium skill & & & 1.024 & $(0.964-1.086)$ & 1.013 & $(0.956-1.075)$ \\
\hline High skill & & & 1.034 & $(0.960-1.115)$ & 1.030 & $(0.952-1.109)$ \\
\hline
\end{tabular}


Table 3 Predictors of birth certification (Continued).

\begin{tabular}{|c|c|c|c|c|}
\hline \multicolumn{5}{|l|}{$\begin{array}{l}\text { Household } \\
\text { characteristics }\end{array}$} \\
\hline $\begin{array}{l}\text { Owns a bank } \\
\text { account }(0 / 1)\end{array}$ & 1.592 & $(1.480-1.700)^{* * *}$ & 1.596 & $(1.483-1.709)^{* * *}$ \\
\hline \multicolumn{5}{|l|}{ Wealth (ref: } \\
\hline \multicolumn{5}{|l|}{ Poor) } \\
\hline Average & 1.300 & $(1.172-1.439) * * *$ & 1.132 & $(1.020-1.253)^{* *}$ \\
\hline Rich & 1.642 & $(1.460-1.841)^{* * *}$ & 1.342 & $(1.170-1.514)^{* * *}$ \\
\hline \multicolumn{5}{|l|}{ Religion (ref: Islam) } \\
\hline Christian & 1.078 & $(0.978-1.185)^{* *}$ & 1.106 & $(0.996-1.215)^{* *}$ \\
\hline Other & 0.867 & $(0.732-1.017)^{*}$ & 0.874 & $(0.730-1.037)$ \\
\hline \multicolumn{5}{|c|}{ Ethnicity (ref: Hausa/Fulani) } \\
\hline Igbo & 1.061 & $(0.953-1.181)$ & 1.061 & $(0.943-1.194)$ \\
\hline Yoruba & 1.146 & $(1.024-1.276)^{* *}$ & 1.168 & $(1.038-1.298)^{* * *}$ \\
\hline Other & 0.943 & $(0.879-1.015)^{*}$ & 0.939 & $(0.869-1.016)^{*}$ \\
\hline \multicolumn{5}{|c|}{$\begin{array}{l}\text { Community } \\
\text { Characteristics } \\
\text { Dist. to Centers (ref: }<5 \mathbf{~ k m s )}\end{array}$} \\
\hline $5-9.99 \mathrm{kms}$ & & & 0.944 & $(0.819-1.089)$ \\
\hline $10+\mathrm{kms}$ & & & 0.780 & $(0.643-0.926)^{* *}$ \\
\hline \multicolumn{5}{|c|}{ Dist. to Roads (ref: $<5 \mathrm{kms}$ ) } \\
\hline $5-9.99 \mathrm{kms}$ & & & 1.095 & $(0.978-1.301)$ \\
\hline $10+\mathrm{kms}$ & & & 1.274 & $(1.053-1.588)^{* *}$ \\
\hline $\begin{array}{l}\text { Average female } \\
\text { education }\end{array}$ & & & 1.021 & $(0.912-0.978)^{* * *}$ \\
\hline Average male education & & & 1.035 & $(1.008-1.071)^{* *}$ \\
\hline$\%$ Poor HHs & & & 0.535 & $(0.396-0.661)^{* * *}$ \\
\hline Child mortality & & & 0.771 & $(0.604-0.894)^{* * *}$ \\
\hline \multicolumn{5}{|l|}{ Region (ref: SW) } \\
\hline $\mathrm{NC}$ & & & 0.974 & $(0.725-1.324)$ \\
\hline $\mathrm{NE}$ & & & 1.595 & $(0.993-2.231)^{* *}$ \\
\hline NW & & & 1.107 & $(0.815-1.522)$ \\
\hline SE & & & 1.064 & $(0.694-1.512)$ \\
\hline SS & & & 0.811 & $(0.560-1.071)^{*}$ \\
\hline
\end{tabular}

Notes: The Empty model (OR=0.045, 95\%CI $=0.034-0.052) ;{ }^{a}$ Model 1: contained only child characteristics; ${ }^{b}$ Model 2: Child plus family characteristics; ${ }^{c}$ Model 3: All characteristics; $\mathrm{OR}=$ Odds ratio; $\mathrm{CI}=$ Credible Interval; ICC: Intra-class Correlation Coefficient; PCV: Proportional Change in Variance; DIC: Deviation Information Criterion *: Change in relation to the previous model. Significance level $* * * p<0.01 * * p<0.05 * p<0.10$ 
Table 4 Regression results for three-level (child-community-state) models of birth certification (Measures of variation)

\begin{tabular}{|c|c|c|c|c|}
\hline Community-level & Model $0^{\mathrm{a}}$ & Model $1^{\mathrm{b}}$ & Model $2^{\mathrm{c}}$ & Model $3^{\mathrm{d}}$ \\
\hline Variance $\tau$ & $2.58 * * *$ & $1.618 * * *$ & $1.211 * * *$ & $1.189 * * *$ \\
\hline$(95 \% \mathrm{CI})$ & $(2.347-2.821)$ & $(1.468-1.780)$ & $(1.092-1.359)$ & $(1.060-1.333)$ \\
\hline $\operatorname{ICC}(\%)$ & 40.91 & 31.62 & 26.15 & 25.94 \\
\hline $\operatorname{PCV}(\%)$ & Reference & 37.29 & 53.06 & 53.91 \\
\hline MOR & 4.63 & 3.36 & 2.86 & 2.83 \\
\hline \multicolumn{5}{|l|}{ State-level } \\
\hline Variance $\tau$ & $0.436 * * *$ & $0.201 * * *$ & $0.133 * * *$ & $0.107 * * *$ \\
\hline$(95 \% \mathrm{CI})$ & $(0.265-0.726)$ & $(0.112-0.331)$ & $(0.071-0.228)$ & $(0.054-0.192)$ \\
\hline $\operatorname{ICC}(\%)$ & 6.92 & 4.00 & 2.85 & 2.34 \\
\hline $\operatorname{PCV}(\%)$ & Reference & 53.90 & 69.50 & 75.46 \\
\hline MOR & 1.88 & 1.53 & 1.42 & 1.37 \\
\hline \multicolumn{5}{|l|}{$\begin{array}{l}\text { Model Fit } \\
\text { Statistics }\end{array}$} \\
\hline DIC & 40082.05 & 39551.09 & 39130.00 & 39090.05 \\
\hline DIC change* & Reference & -530.96 & -421.09 & -39.95 \\
\hline $\mathrm{N}$ & 79487 & 79487 & 79487 & 79487 \\
\hline \multicolumn{5}{|c|}{$\begin{array}{l}\text { Notes: }{ }^{\mathrm{a}} \text { Model 0: Null (Empty) model; }{ }^{\mathrm{b}} \text { Model } 1 \text { : contained only child characteristics; }{ }^{\mathrm{c}} \text { Model } 2 \text { : Child } \\
\text { plus family characteristics; }{ }^{\mathrm{d}} \text { Model } 3: \text { All characteristics; OR = Odds ratio; CI = Credible Interval; ICC } \\
\text { Intra-class Correlation Coefficient; PCV: Proportional Change in Variance; DIC: Deviation Information } \\
\text { Criterion *: Change in relation to the previous model; N: Number of observations }\end{array}$} \\
\hline
\end{tabular}




\section{Figures}

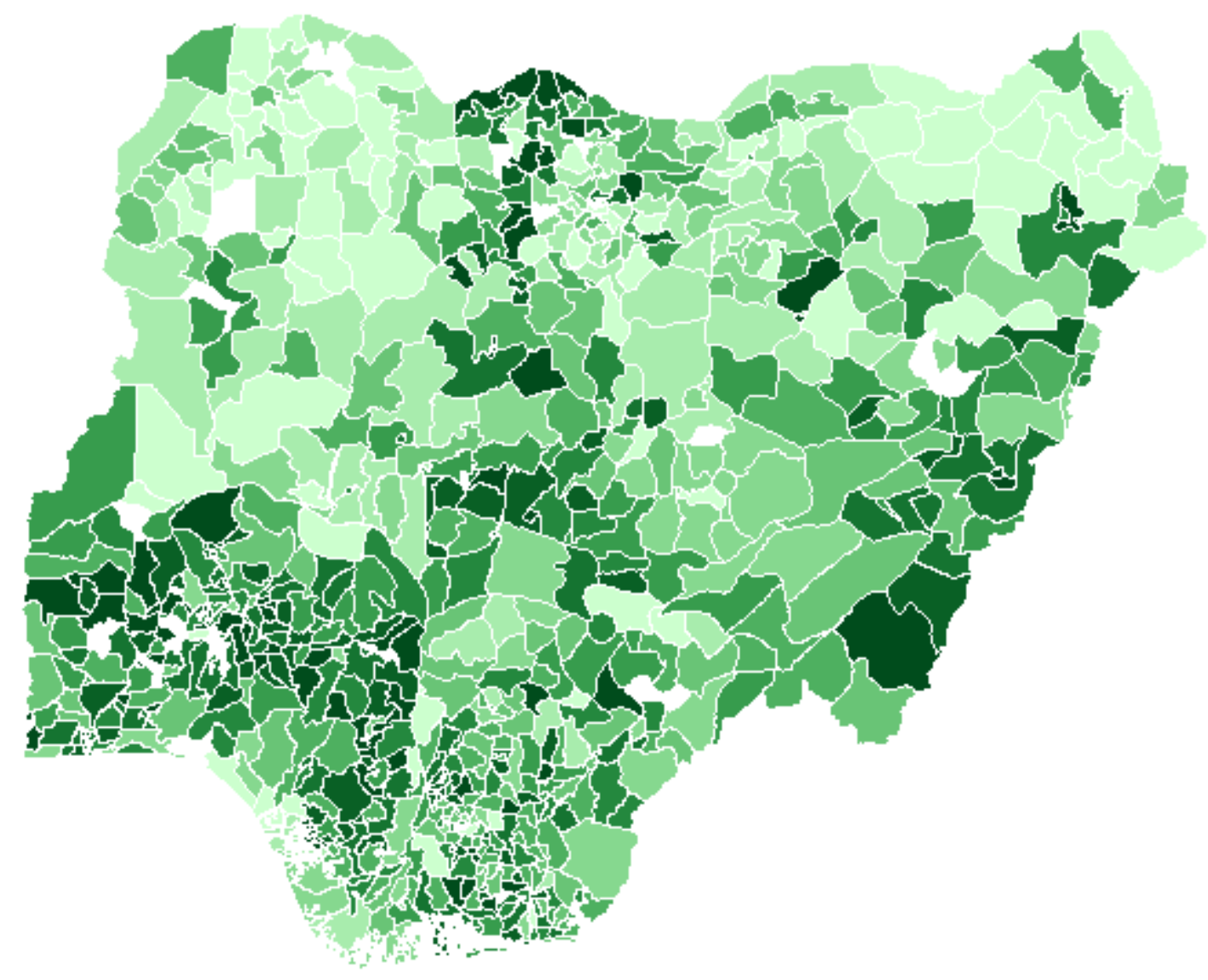

\section{Figure 1}

Birth certification rates among children under-five years, across 774 local government areas (LGAs), Nigeria, pooled data, 2008-2018 

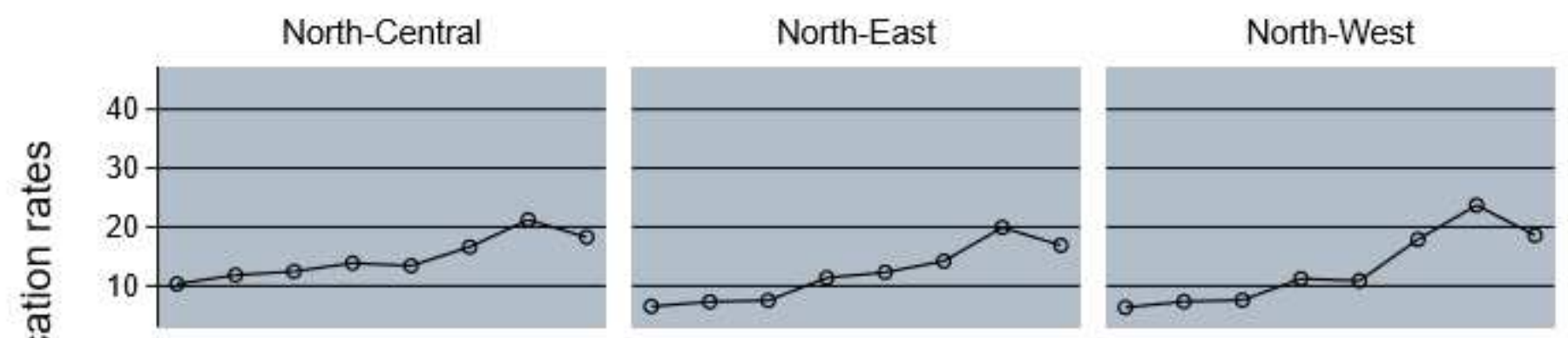

South-East

South-South

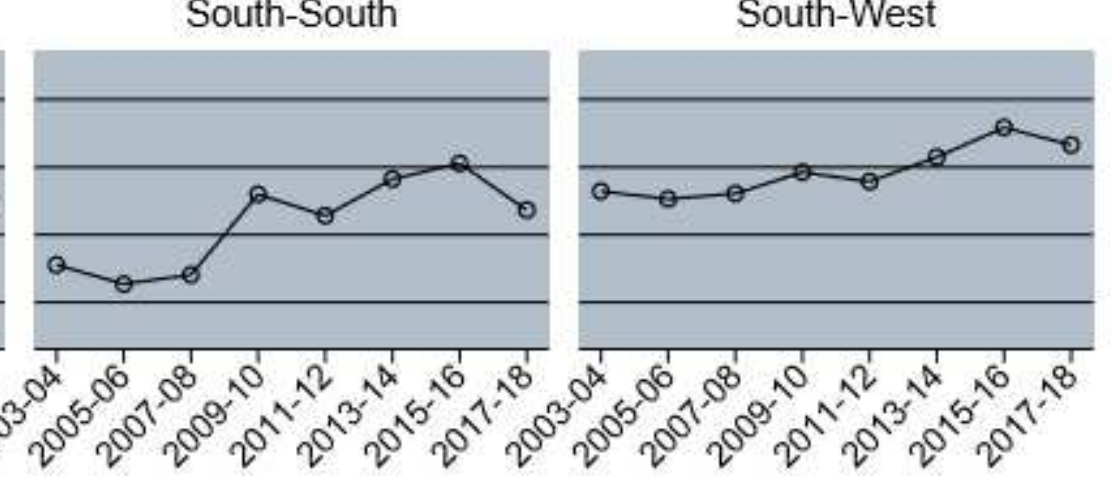

Child's year of birth

- meancertified

Graphs by Geo-political region

\section{Figure 2}

Prevalence of birth certification by region of residence and birth year, Nigeria, pooled data 2008-2018

\section{Supplementary Files}

This is a list of supplementary files associated with this preprint. Click to download.

- DetBirthCertificationSupplementaryData.pdf 